\title{
Port Container Terminal Quay Crane Allocation Based on Simulation and Machine Learning Method
}

\author{
Indranath Chatterjee ${ }^{1}$ and Gyusung $\mathrm{Cho}^{2 *}$ \\ ${ }^{1}$ Department of Computer Engineering, Tongmyong University, \\ 428, Sinseon-ro, Nam-gu, Busan 48520, Republic of Korea \\ ${ }^{2}$ Department of Port Logistics System, Tongmyong University, \\ 428, Sinseon-ro, Nam-gu, Busan 48520, Republic of Korea
}

(Received September 6, 2021; accepted December 2, 2021; online published January 12, 2022)

Keywords: container terminal, quay crane, port operation, simulation method, machine learning, data analysis, IoT sensors

Container terminals play a crucial role in exporting and importing goods, where export and import containers are loaded and unloaded. Containers are usually loaded and unloaded with a dock crane. A quay crane is assigned at a container port in advance, considering a ship's arrival schedule. However, allocating a quay crane is difficult owing to the limited number of quay cranes available and the need to consider the shipping timetable. In this study, by considering the schedule of each ship arriving from a container terminal, the number of unloaded containers for each ship, and the limited number of quay cranes, we conduct quay crane assignment through a simulation model to increase the productivity of a container terminal. Alongside, it is evident that artificial intelligence (AI) and machine learning (ML) are necessary for port management in many ways, from berth scheduling to quay allocation. In this study, we also investigate the applicability of ML and metaheuristic approaches in quay allocation problems and explore further possibilities. In this study, we also highlight the sensor-based automation of quay allocation using Internet of Things (IoT) technologies for future research in the domain of port and terminal management.

\section{Introduction}

First-generation ports centered on cargo handling have developed into second- and thirdgeneration ports, which were the basis for logistics and trade activities, and into fourthgeneration ports where various information provisions and automated loading and unloading have been realized. ${ }^{(1,2)}$ As ports continue to develop, the efficient operation of container terminals is becoming increasingly important. ${ }^{(3,4)}$ To increase the operational efficiency of container terminals, a performance estimation has recently been conducted using simulation methods. ${ }^{(5)}$ In particular, in the analysis of container terminal operations, the proper arrangement of the quay crane (QC) is essential because the operational efficiency of the container terminal is improved according to the crane arrangement and operation when used in the quantitative

\footnotetext{
*Corresponding author: e-mail: gscho@tu.ac.kr
} 
loading and unloading of containers. ${ }^{(6)}$ Therefore, as one of the methods for improving the performance of container cranes, we focus on the assignment of quay wall cranes in container terminals based on a simulation in this study.

A simulation is the best tool for analyzing nontrivial and real-world systems. ${ }^{(7,8)}$ Simulation methods have become an essential tool for improving terminal operation and performance. Busan Port is an international port with more than 30 berths, which ranks sixth globally in container throughput as of 2020. Thus, the simulation framework is based on a container terminal company located in Busan, Korea. ${ }^{(9,10)}$ We analyze and suggest operations for improving the container productivity for assigning QCs using a simulation method.

Recently, machine learning (ML) has played a significant role in port management in many ways, starting with berth scheduling to quay allocation. Alternatively, ML is necessary for transportation systems to provide smart solutions to a variety of situations. Although there has been a significant focus on optimization and simulation modeling in port studies, ML has helped create more sophisticated prediction models for improved port operations. We conducted this study to assess the contributions of ML to port operations.

Even simpler forms of the quay allocation problem are known to be nondeterministic polynomial (NP) time hard. Therefore, metaheuristic techniques are preferable to precise methods since they give high-quality answers in a reasonable amount of time. Metaheuristics are broad frameworks for developing heuristic algorithms for challenging tasks. Recently, different metaheuristic approaches have also performed well with quay allocation. A summary of commonly utilized metaheuristic approaches for solving the quay allocation problem is also provided in this study. The sensors using Internet of Things (IoT) technologies could be a new paradigm for quay allocation, and studying the transformation of conventional ports into smart ports is essential. In this study, we also briefly discuss the possibilities of sensor-based IoT techniques in the problem of port management.

\section{Container Terminal Operation}

Basic facilities such as a quay, marshaling, container yard, and gate are required to load, unload, store, and mix cargo in a container terminal. Various types of equipment, such as QCs, are placed in these facilities to process containers. A container terminal is a facility where cargo containers are transshipped between different transport vehicles for onward transportation. Containers from ships docked in a berth are loaded and unloaded using the quay wall crane. Each ship is given QC duties before docking at the port container terminal, and containers are loaded and unloaded for each assigned ship. The quay wall crane is a device that carries containers to the ships at the port container terminal and plays the most crucial role there. Figure 1 shows a photograph of a QC.

Figure 2 shows a flow chart of the quay QC assignment, loading and unloading, and departure after berthing in an empty berth after a ship enters the port at the container terminal. As shown in Fig. 2, the QC must be assigned before the ship docks. If the QC is not assigned, the container loading and unloading operations are not fulfilled. ${ }^{(11,12)}$ 


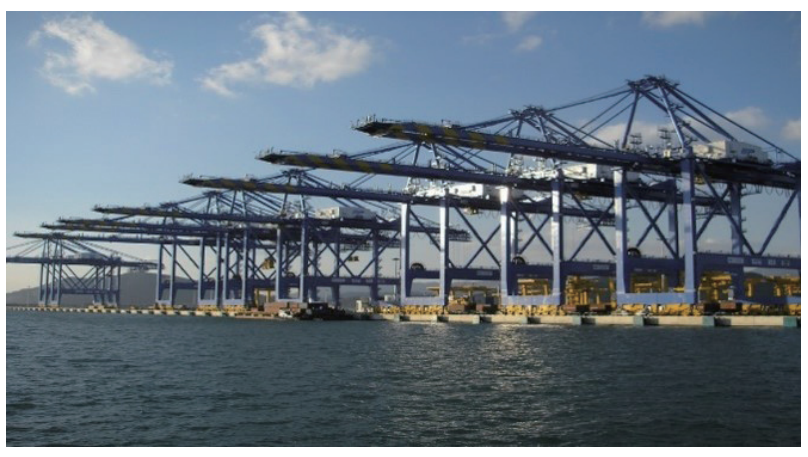

Fig. 1. (Color online) Quay cranes (image taken from https://www.pncport.com).

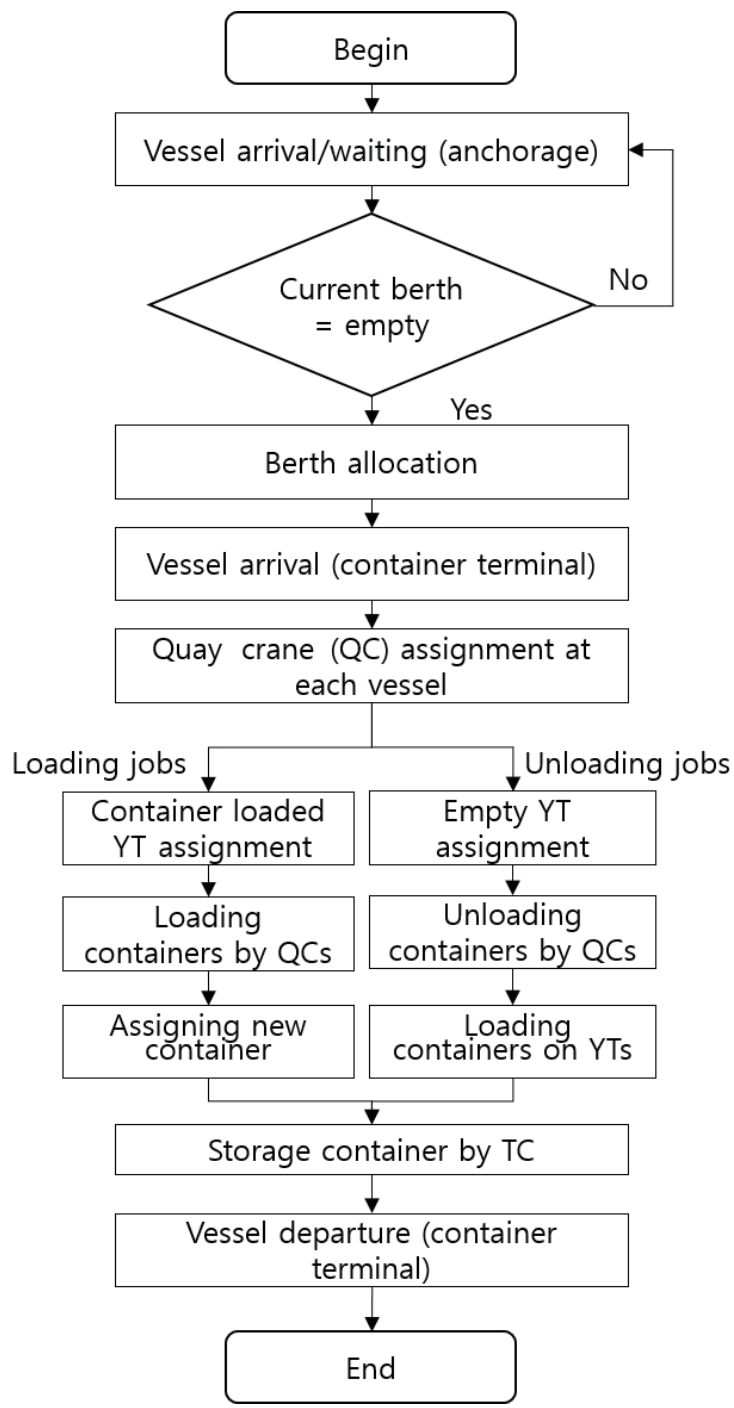

Fig. 2. Flow chart of container terminal.

The process shown in Fig. 2 can be described in more detail as follows. There are two container terminal operations. 
A. Loading operation

- Lifting export containers using transfer cranes (TCs) in a container yard

- Placing containers on yard tractors (YTs) in container yards

- Placing them in a ship's bay using QCs

B. Unloading operation

- Lifting import containers by gantry cranes into a ship's bay

- Placing them on yard tractors sent to the container yard

In particular, the QC plays the most critical role in a container terminal as equipment for loading and unloading containers from container terminals to ships. ${ }^{(13)}$

\section{ML and Metaheuristic Approaches Involving Quay Allocation}

ML is the study of teaching computers to learn and act like people and enhance their learning over time in an autonomous way, using data and information fed to them in the form of observations and real-world interactions. ${ }^{(14)}$ Terminal planning and management must be reviewed from a data-driven viewpoint, given the new potential arising from the current wave of digitization in all aspects of global logistics chains. We evaluated the present state-of-the-art literature about applications of ML in the context of container terminals to create a data-driven viewpoint on terminal design and management. The extent of such efforts within the operational areas of port management, especially in quay allocation, is briefly summarized in the following.

León et al. ${ }^{(15)}$ discussed berth scheduling operations by considering the berth allocation problem. The authors demonstrated ML as a tool for identifying the suitable algorithm for berth allocation. Similarly, a study by Wang and Ding ${ }^{(16)}$ explored the applicability of ML to the QC allocation problem using an ML-based ensemble model. They analyzed the large amount of historical data based on influencing factors and QC usage time. They proposed a multifactor ensemble learning estimation model, which found that the Adaboost algorithm seems to be efficient. Mekkaoui et al. ${ }^{(17)}$ performed a systematic review on applications of ML algorithms in port management. They reported an elaborative analysis of the applied algorithms, discussed their results, and highlighted the research gaps for further studies.

Metaheuristic optimization is concerned with the use of metaheuristic methods to resolve optimization issues. From engineering to economics and from vacation planning to Internet routing, optimization is practically everywhere. ${ }^{(18)}$ Recently, metaheuristic approaches have been attracting much attention in port and logistics management, specifically in QC optimization problems for berth and quay allocation.

Tavakkoli-Moghaddam et al. ${ }^{(19)}$ presented a mixed-integer programming (MIP) model for a container terminal's QC scheduling and assignment problem. The authors proposed a genetic algorithm to solve the QC problem, and they also compared the efficiency of the proposed GA with the LINGO software package. The results suggested that the proposed GA can solve the QC allocation problem with a significant management size. Similarly, Krčum et al. ${ }^{(20)}$ proposed an optimization technique for scheduling berth and QCs using a genetic algorithm. RodriguezMolins et al. ${ }^{(21)}$ also devised a genetic-algorithm-based approach for berth QC allocation. They focused on scheduling several incoming vessels by assigning each a berthing position and 
allocating the QCs. They applied a mixed-integer linear programming model to minimize the total weighted service time of the incoming vessels. Atencio and Casseres ${ }^{(22)}$ also discussed the three well-known metaheuristics for determining the optimal berthing sequence to optimize the total cost when allocating a fixed number of vessels.

In this paper, we propose an ML-based approach and metaheuristic algorithms for solving QC allocation problems for large ports, where the number of vessels is large. In our future study, we will be exploring their applicability to the real-time data obtained from a busy and large port, such as Busan Port. This observation may be beneficial for further research in the domain of port management and QC allocation to optimize the above-mentioned problem and automate port management for smoother and faster operation.

Internet of Things (IoT) plays a crucial role in establishing smart ports. Different operating sectors are now working in the automated mode as smart sensing systems in ports become a reality. A smart port is a wholly automated port that connects all devices via the IoT Smart Port. The smart port's primary infrastructure consists of a network of smart sensors and actuators, wireless devices, and data centers, allowing port authorities to perform essential services faster and more effectively. The deployment of an autonomous container terminal necessitates sensing systems for duties, such as quayside crane structural health monitoring, container position detection and handling, automatic guided vehicle localization, navigation, and control.

\section{Computational Data Analysis}

The input data for the QC assignment of container terminals are shown in Table 1. The port has two berths, with an annual container throughput of 1,000,000 twenty-foot equivalent unit (TEU) and a total berth length of $600 \mathrm{~m}$. There are six QCs used for loading and unloading ships from the berth and 18 rubber-tired gantry cranes (RTGCs) for loading containers in the yard. There are 38 YTs for transporting containers from the container terminals.

Table 2 shows the arrival and departure information of ships arriving at the container terminal. In addition, Table 2 illustrates the present status of the port container terminal at Busan Port and the ship assignment of quay wall cranes. The arrival/departure information includes the vessel ID, arrival time, and departure time. In this study, the proper distribution of quay wall cranes was based on the ships' actual arrival and departure information. For the proper distribution of quay wall cranes, as shown in Table II, a distribution problem was solved by considering the arrival and departure information of a total of 17 ships and the QC of six

Table 1

Input data.

\begin{tabular}{lr}
\hline Items & Values \\
\hline Stacking capacity (TEU) & 1000000 \\
Ship births & 2 \\
Total length of berth (meter) & 600 \\
QC & 6 \\
RTGC & 18 \\
YT & 38 \\
Gate & 6 \\
\hline
\end{tabular}


Table 2

Ship arrival/departure time.

\begin{tabular}{lcccc}
\hline ID & Arrival time & Departure time & Total stay time (s) & $\begin{array}{c}\text { Total stay hour } \\
\text { (hour:min) }\end{array}$ \\
\hline KHGB003 & $2018-02-28$ 08:16 & $2018-03-0106: 00$ & 78240 & $21: 44$ \\
MOMX001 & $2018-02-2814: 15$ & $2018-03-0114: 00$ & 85500 & $23: 45$ \\
DWFM009 & $2018-02-2816: 11$ & $2018-03-0103: 00$ & 38940 & $10: 49$ \\
ATSO006 & $2018-02-2816: 30$ & $2018-03-0110: 00$ & 63000 & $17: 30$ \\
UNAH002 & $2018-02-2819: 00$ & $2018-03-0200: 00$ & 104400 & $29: 0$ \\
ZZOP002 & $2018-02-2820: 10$ & $2018-03-0116: 33$ & 73380 & $20: 23$ \\
NBHS006 & $2018-03-0104: 06$ & $2018-03-0108: 00$ & 14040 & $3: 54$ \\
SMHM009 & $2018-03-0110: 50$ & $2018-03-0119: 00$ & 29400 & $8: 10$ \\
NBIL003 & $2018-03-0111: 00$ & $2018-03-0120: 00$ & 32400 & $9: 0$ \\
KHBB001 & $2018-03-0112: 05$ & $2018-03-0201: 00$ & 46500 & $12: 55$ \\
YEMI003 & $2018-03-0116: 05$ & $2018-03-0212: 00$ & 71700 & $19: 55$ \\
EADL009 & $2018-03-0118: 18$ & $2018-03-0203: 00$ & 31320 & $8: 42$ \\
NSVY005 & $2018-03-0120: 36$ & $2018-03-0202: 00$ & 19440 & $5: 24$ \\
NNAE001 & $2018-03-0122: 00$ & $2018-03-0210: 00$ & 43200 & $12: 0$ \\
SYMX001 & $2018-03-0202: 14$ & $2018-03-0305: 00$ & 96360 & $26: 46$ \\
STRT001 & $2018-03-0203: 17$ & $2018-03-0301: 00$ & 78180 & $21: 43$ \\
CAUX001 & $2018-03-0206: 10$ & $2018-03-0310: 00$ & 100200 & $27: 50$ \\
\hline
\end{tabular}

ships. In the quay wall crane, work is conducted every $90 \mathrm{~s}$, and in the YT, container work is conducted for $15 \mathrm{~s}$, and inspection work is applied for $10 \mathrm{~s}$. Each TC waiting in the yard is set to perform an unloading operation every $60 \mathrm{~s}$.

\subsection{Integrated aspect-oriented modeling approach}

The aspect-oriented modeling approach (AOMA) has been applied to enhance the performance of the simulation system. AOMA is a programmatic mechanism using crosscutting concerns. It can be developed separately and then combined with an executing code of different classes. An improved aspect-oriented modeling approach (i-AOMA) helps apply the suggested concept to a real case study. ${ }^{(11)}$ i-AOMA includes two methods, namely, objectoriented modeling and aspect-oriented modeling. Object-oriented modeling can be conducted after defining the object construct, which allows one-to-one mapping between objects in the system and their abstractions in the object model. Aspect-oriented modeling comprises attributes controlling the simulation model, configured by the declaration in aspect-oriented modeling, consisting of codes and data merged into an indivisible object (object-oriented modeling). In this study, i-AOMA is based on aspect-oriented programming, making it possible to express programs, including appropriate isolation, composition, and the reuse of the aspect code (Fig. 3). i-AOMA is built on a conceptual framework and denotes the space of modeling elements for specifying cross-cutting concerns at a higher abstraction level. 


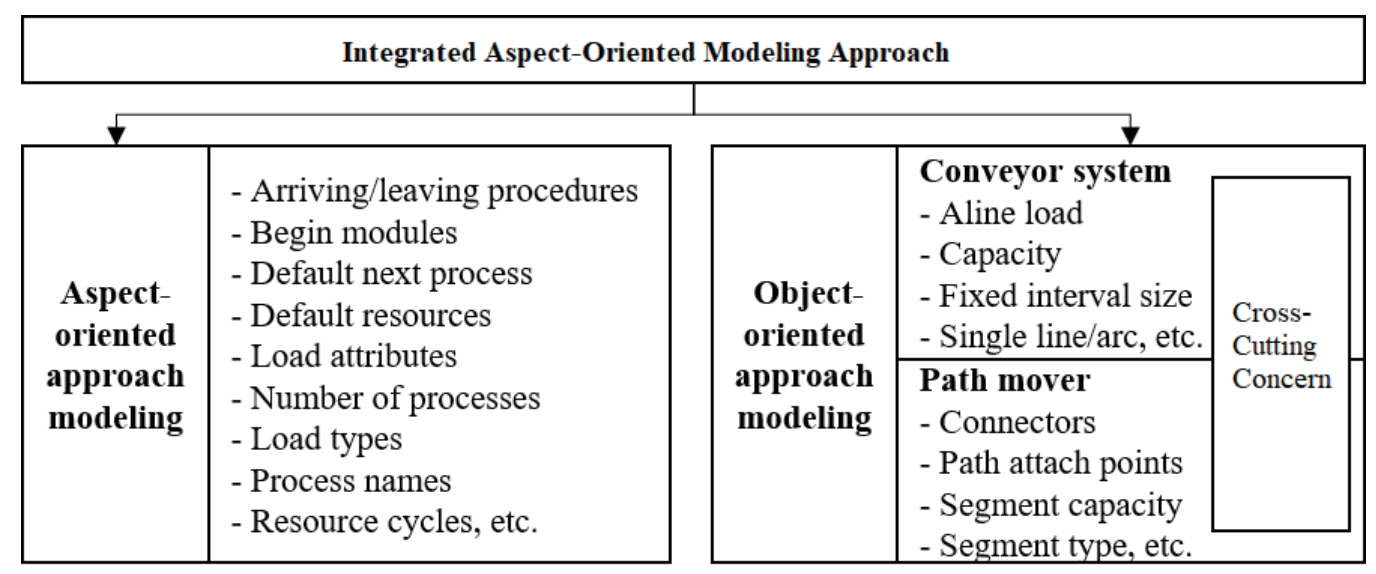

Fig. 3. Concept of integrated aspect-oriented modeling approach.

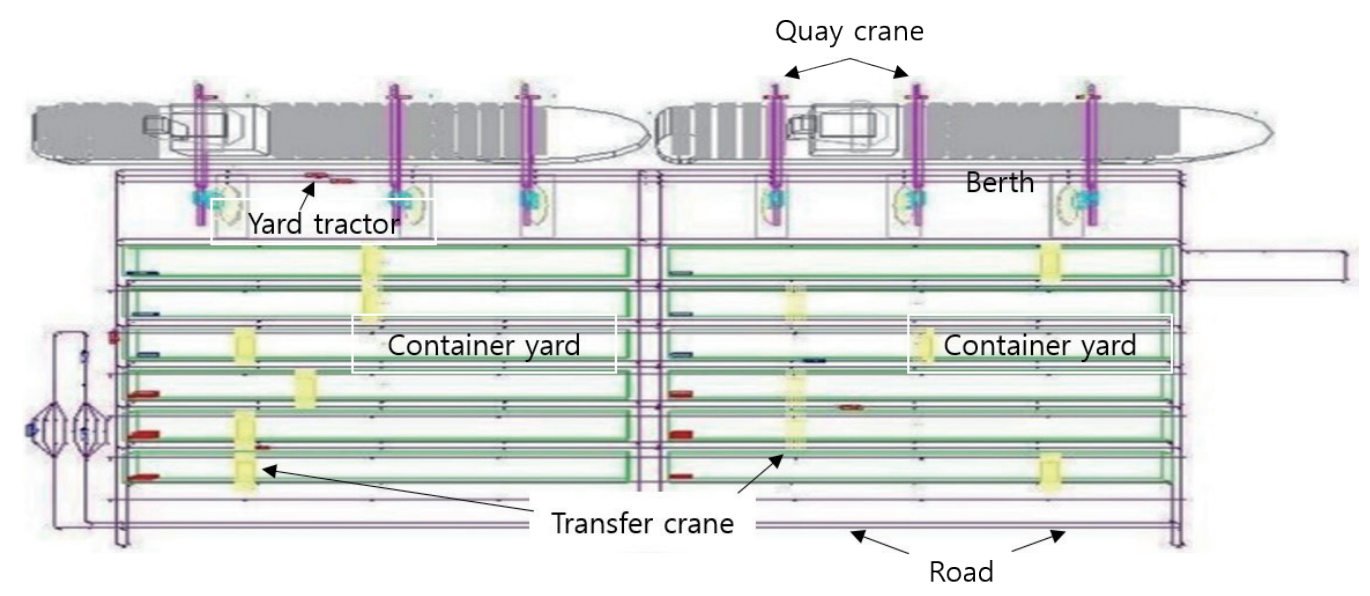

Fig. 4. (Color online) Quay crane allocation model.

\subsection{Quay crane assignment simulation model}

In this study, we focus on the allocation of QCs operated in container terminals. A simulation model was constructed and analyzed to carry out this study, as shown in Fig. 3. For this study, the AutoMod system was applied for modeling, and operation was performed for one year on an Intel Xeon W-2123 CPU at $3.6 \mathrm{GHz}$ with $64 \mathrm{~GB}$ of RAM. Figure 4 shows the simulation model considering the allocation of the QCs. ${ }^{(23)}$

Figure 4 also shows the container handling status of the quay wall crane. QCs are used from QC33 to QC84, and one month's worth of data is considered. A vessel is assigned to each QC. Because the quay wall cranes are operated for one year and the throughput of the quay wall varies according to the allocation for each berth, the work assignment number of the quay wall crane is determined according to the work status, as shown in Fig. 4. As a result of the QC assignment, it can be seen that an average of 30-40 TEUs per hour are processed per QC, and no more than 50 at most are processed. 
Figure 5 shows the scatter chart showing the layover of the vessels at the port and their total staying time. Figure 6 shows the distribution of QCs considering the arrival and departure of the ships and TUEs processed by each QC. Figure 7 shows the number of containers for cargo handling by ships. The QC throughput considering the arrival and departure was found to be 30-45 TEUs.

Table 3 shows the current status of the processing by quayside cranes and related equipment. It can be seen that a maximum of 1680 pieces are stored for each of the 12 blocks, and an average of 82.83 pieces are stored per cabinet. In addition, it can be seen that $50 \%$ of the maximum storage capacity of 300 units is not reached because a maximum of 132 pieces are stored in each storage unit.

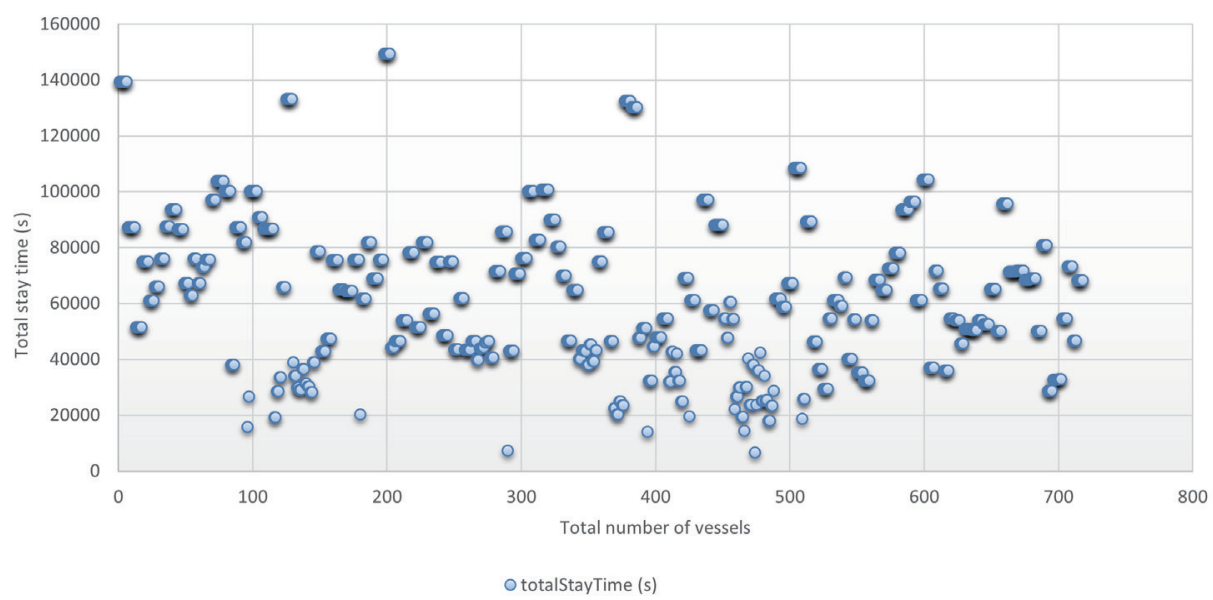

Fig. 5. (Color online) Number of vessels staying in the port and their total staying time (s).

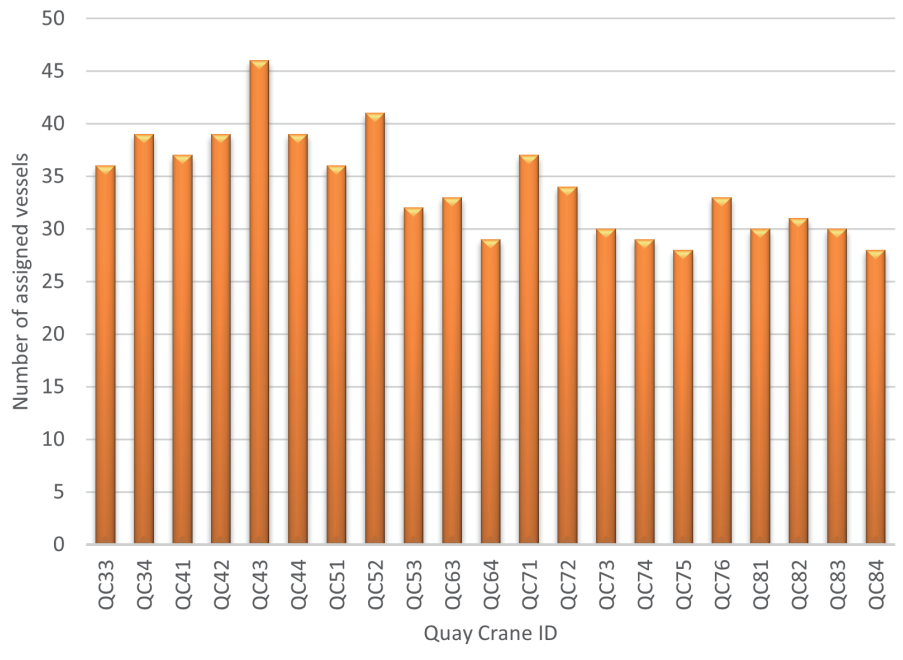

Fig. 6. (Color online) Quay crane handling throughput. 


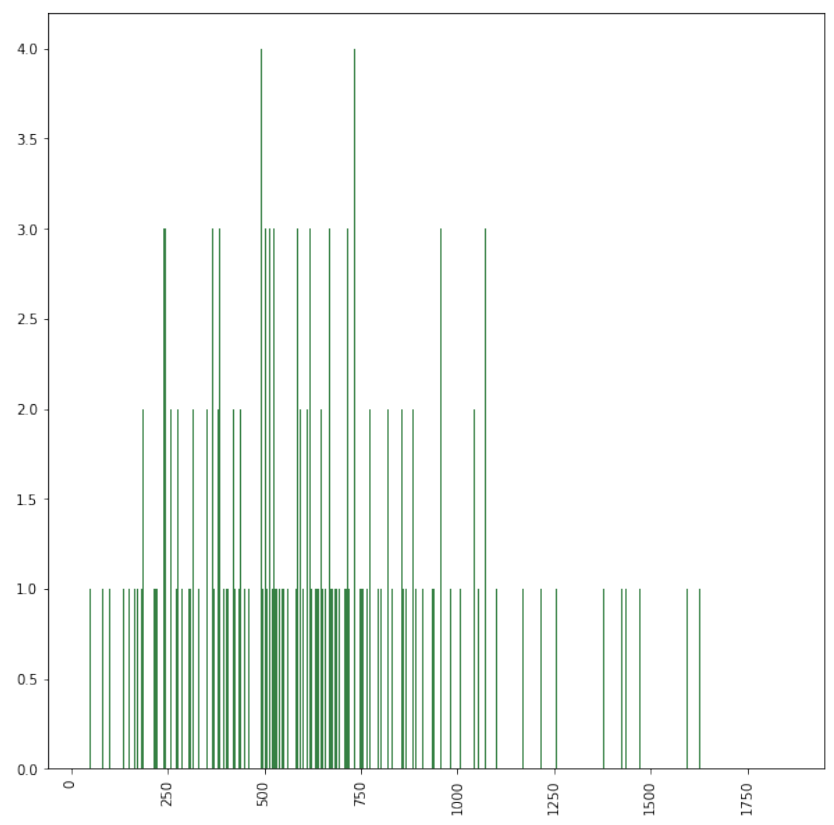

Fig. 7. (Color online) Number of load/unloaded TEUs by vessels.

Table 3

Processing status by equipment plant (unit: TEU).

\begin{tabular}{lccccc}
\hline Name & Total & Average & Max & Min & Capacity \\
\hline Block(1) & 170 & 75 & 156 & 0 & 300 \\
Block(2) & 132 & 58 & 117 & 0 & 300 \\
Block(3) & 118 & 51 & 104 & 0 & 300 \\
Block(4) & 127 & 56 & 125 & 0 & 300 \\
Block(5) & 166 & 74 & 164 & 0 & 300 \\
Block(6) & 127 & 56 & 125 & 0 & 300 \\
Block(7) & 164 & 72 & 144 & 0 & 300 \\
Block(8) & 143 & 63 & 131 & 0 & 300 \\
Block(9) & 113 & 49 & 102 & 0 & 300 \\
Block(10) & 164 & 76 & 163 & 0 & 300 \\
Block(11) & 137 & 65 & 137 & 0 & 300 \\
Block(12) & 119 & 59 & 117 & 0 & 300 \\
\hline Total & 1680 & \multicolumn{7}{c}{0} & \\
\hline Average & \multicolumn{7}{r}{} & 82.83 & 132.08 & 0 & 300 \\
\hline
\end{tabular}

\section{Conclusions}

As container terminals shift to large-scale automation, the number of containers to be processed is increasing. For this reason, it is necessary to operate the limited port equipment in a container terminal efficiently. In this study, we focus on the allocation of QCs used in container terminals. The quantitative loading and unloading of the containers were performed by assigning QCs to each berth for efficient processing. For the assignment of quay wall cranes, their operational feasibility was presented through model construction, and an analysis was conducted 
through a simulation method. We also looked at the applicability of ML and metaheuristic techniques to the quay allocation problem in this research and looked into other options. This work may shed insight into AI-based computational aspects of quay allocation for future research in the sector. In the future, we plan to study the assignment of quay wall cranes by receiving actual data operated at the container terminal in real time.

\section{Acknowledgments}

This work was supported by a National Research Foundation of Korea (NRF) grant funded by the Korean government (MSIP), grant number NRF-2021R1I1A3046794.

\section{References}

1 B. Feng and Q. Ye: Front. Eng. Manage. 8 (2021) 344. https://doi.org/10.1007/s42524-021-0156-2

2 A. Martínez-Gutiérrez, J. Díez-González, R. Ferrero-Guillén, P. Verde, R. Álvarez, and H. Perez: Sensors 21 (2021) 3344. https://doi.org/10.3390/s21103344

3 M. Kim, S. Park, Y. Kim, H. Lee, and G. Yeo: J. Digital Converg. 19 (2021) 117. https://doi.org/10.14400/ JDC.2021.19.2.117

4 G. Cho, H. Kim, and M. Kim: ICIC Exp. Lett. Part B: Appl. 8 (2017) 633. https://doi.org/10.24507/ icicelb.08.03.633

5 T. Kim and J. Lee: J. Korean Soc. Agric. Eng. 51 (2009) 43. https://doi.org/10.5389/KSAE.2009.51.2.043

6 G. Tang, M. Qin, Z. Zhao, J. Yu, and C. Shen: Simul. Modell. Pract. Theory 104 (2020) 102129. https://doi. org/10.1016/j.simpat.2020.102129

7 W. Y. Yun and Y. S. Choi. Int. J. Prod. Econ. 59 (1999) 221. https://doi.org/10.1016/S0925-5273(98)00213-8

8 J. Choi: J. Korea Contents Assoc. 21 (2021) 454. https://doi.org/10.5392/JKCA.2021.21.03.454

9 T. Adi, Y. Iskandar, and H. Bae: Sensors 20 (2020) 5794. https://doi.org/10.3390/s20205794

10 G. Cho and H. Kim: Int. J. Ind. Eng. Theory Appl. Pract. 20 (2013) 24. https://journals.sfu.ca/ijietap/index.php/ ijie/article/view/506

11 G. Cho and S. Lee: Electronics 9 (2020) 1. https://doi.org/10.3390/electronics9101615

12 V. Elia and M. Gnoni: Int. J. Prod. Econ. 170 (2015) 730. https://doi.org/10.1016/j.ijpe.2015.05.030

13 M. Stojaković and E. Twrdy: Eur. Transport Res. Rev. 13 (2021) 1. https://etrr.springeropen.com/ articles/10.1186/s12544-021-00482-6

14 A. Gautam and I. Chatterjee: Int. J. Oper. Res. Inf. Syst. 11 (2020) 19. https://doi.org/10.4018/ IJORIS.2020070102

15 A. León, E. Lalla-Ruiz, B. Melián-Batista, and J. Moreno-Vega: Expert Syst. Appl. 87 (2017) 170. https://doi. org/10.1016/j.eswa.2017.06.010

16 G. Wang and Y. Ding: J. Manage. Sci. Eng. Res. 3 (2021) 31. https://doi.org/10.30564/jmser.v3i2.2689

17 S. Mekkaoui, L. Benabbou, and A. Berrado: Proc. 2020 5th Int. Conf. Logistics Operations Management (GOL, 2020) 1-5. http://doi.org/10.1109/GOL49479.2020.9314756

18 I. Chatterjee, V. Kumar, B. Rana, M. Agarwal, and N. Kumar: Multimedia Syst. 26 (2020) 383. https://doi. org/10.1007/s00530-020-00649-6

19 R. Tavakkoli-Moghaddam, A. Makui, S. Salahi, M. Bazzazi, and F. Taheri: Comput. Ind. Eng. 56 (2009) 241. https://doi.org/10.1016/j.cie.2008.05.011

20 M. Krčum, A. Gudelj, and S. Vlahinic: Proc. 2007 2nd Int. Conf. Ports and Waterways (2007) 165-177. http://161.53.22.65/datoteka/318152.165-177.pdf

21 M. Rodriguez-Molins, F. Barber, M. Sierra, J. Puente, and M. Salido: Proc. 2012 Ibero-American Conf. Artificial Intelligence (2012) 601-610. https://doi.org/10.1007/978-3-642-34654-5 61

22 F. Atencio and D. Casseres: IFAC-PapersOnLine. 51 (2018) 1281. https://doi.org/10.1016/j.ifacol.2018.08.356

23 AutoMod Manual: https://www.appliedmaterials.com/automation-software/automod (accessed October 2021). 


\section{About the Authors}

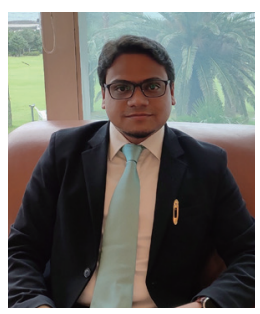

Indranath Chatterjee is a visiting professor in the Department of Computer Engineering at Tongmyong University, Busan, South Korea. He received his $\mathrm{Ph} . \mathrm{D}$. degree in computational neuroscience from the Department of Computer Science, University of Delhi, India. His research areas include computational neuroscience, schizophrenia, medical imaging, fMRI, and machine learning. To date, he has authored and edited eight books on computer science and neuroscience published by renowned international publishers and has published numerous research papers in international journals and conferences. $\mathrm{He}$ is a recipient of various global awards on neuroscience. He is an active professional member of the ACM, USA; OHBM, USA; FENS, Belgium; ACNM, India; and INCF, Sweden. (indranath.cs.du@gmail.com)

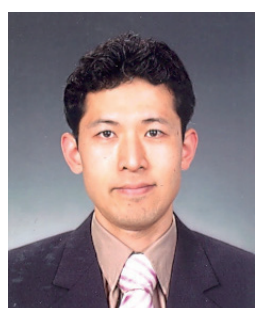

Gyusung Cho received his BS, MS, and Ph.D. degrees from Dong-Eui University, Republic of Korea, in 1998, 2000, and 2003, respectively. Since 2012, he has been a professor at Tongmyong University. His research interests are in port logistics systems, system design and analysis, and simulation. (gscho@tu.ac.kr) 